\title{
Performance Measurement and Management Systems: A Perspective from Complexity Theory
}

\author{
Simon Okwir, Sai S. Nudurupati, ${ }^{1}$ Matías Ginieis ${ }^{2}$ and Jannis Angelis ${ }^{3,4}$ \\ Stockholm Business School, Stockholm University, SE-106 91, Stockholm, Sweden, ${ }^{1}$ GITAM School of International \\ Business, Gandhi Institute of Technology and Management, Gandhi Nagar, Rushikonda, Visakhapatnam-530045, \\ Andhra Pradesh, India, ${ }^{2}$ Universitat Rovira i Virgili, Tarragona, Spain, ${ }^{3} \mathrm{KTH}$ - Royal Institute of Technology, School of \\ Industrial Engineering and Management, Lindstedtsvägen 30, 114 28, Stockholm, Sweden, and ${ }^{4}$ Research Institute of \\ Industrial Economics, Grevgatan 34, SE-10215, Stockholm, Sweden \\ Corresponding author email: simon.okwir@sbs.su.se
}

\begin{abstract}
Complexity negatively impacts the process of continually improving performance management systems (PMSs). The extant PMS literature considers complexity to be a result of the external environment rather than a user response to that environment. However, this paper argues that organizations generally face internal complexity when adopting PMSs. Introducing PMSs into an organization can have varied effects in those organizations based on the complexity of an organization's associated members and its interactions. This study aims to understand the emergence of complexities while implementing and using PMSs in organizations. From the complexity theory perspective, four system properties (ontological, teleological, genetic and functional) are used to understand complexity in PMSs. The paper builds on a systematic literature review consisting of 76 papers and analyses them in the light of exploring sources of complexity when implementing and using PMSs. From the outset, complexity is understood to be a result of the conflict between existing organizational practices and mechanisms and the organizational controls associated with PMSs. The key findings abstracted six sources of complexity in this study: role, task and procedural types of complexity associated with the social dimension, and methodological, analytical and technological types of complexity associated with the technical dimension. The study findings contribute to the current discussion regarding why PMSs typically lag and are not responsive and resilient in emerging contexts. While understanding and exploring all organizational controls that moderate a PMS is useful, organizations should construct the necessary capabilities, depending on their context and adapt to the changes associated with PMSs.
\end{abstract}

\section{Introduction}

Performance management systems (PMSs) have been posited as processes that help organizations set goals

\footnotetext{
This document has been produced with funding from Education Audiovisual and Culture Executive Agency (EACEA) of European Commission within the framework of the European Doctorate in Industrial Management (EDIM). The authors would like to acknowledge the helpful comments from the anonymous reviewers and MUSICA research group at Stockholm Business School.
}

and track progress over time. However, growing environmental and organizational complexity has become a barrier to implementing efficacious PMSs (Harkness and Bourne 2015; Rahbek et al. 2012). While external environmental complexity has been a focus of several academic studies (Harkness and Bourne 2015; Melnyk et al. 2014; Nudurupati et al. 2016), internal organizational complexity has been ignored by scholars in the extant performance measurement and management (PMM) literature (Braz et al. 2011; Franco-Santos et al. 2007). With the introduction of 
total quality management (TQM) in the 1980s and the revolution of traditional backward-looking accounting systems in the 1990s, teams of individuals, using performance measurement (PM) from within their functional area, became responsible for decisionmaking. In essence, organizations adopted structures that are naturally distributed alongside hierarchies in which information is exchanged laterally through the organization. However, this distribution opposed the top-down flow of strict hierarchies of command and control structures that already existed to manage the organization, thus resulting in complexity (Adler 2011; Burnes 2005; Lin et al. 2014; Zellner 2008).

According to complexity theory, if organizations are considered to be complex and non-linear systems, their associated members and their interaction with subsystems will determine their current and future behaviour through a self-organizing set of ordergenerating rules (Brown and Eisenhardt 1997). Even light and relatively insignificant turbulence can lead to a huge change with unpredictable consequences and vice versa. Therefore, PMSs that are introduced into an organization can have varied effects on those organizations, based on the complexity of their associated members and its interactions. According to Stacey (1995), there are three types of these varied effects. In the first type, the PMS has no impact on the organization, in which case the system soon becomes obsolete. In the second type, the PMS can bring uncontrolled instability into the organization, in which case it self-destructs. In the final type, the PMS can bring controlled instability, in which case the organization is able to adapt to the change in order to survive. Therefore, to understand complexity in the PMS context, it is necessary to understand the role of PMSs as agents of change (Bourne et al. 2000; Nudurupati et al. 2011).

To begin understanding complexity of a PMS, it is necessary to understand its life cycle from its design through implementation and use (including revisions) (Bourne et al. 2000). These process stages have been part of previous discussions in several studies (Bourne et al. 2003; Deng et al. 2012; Jääskeläinen and Sillanpää 2013; Lohman et al. 2004; Nudurupati et al. 2011; Suprapto et al. 2009). All three stages are equally important and key to a PMS's success or failure, depending on the way organizations have adopted the PMS in different contexts (Bititci et al. 2012; Choong 2013; Folan and Browne 2005; MasonJones and Towill 2000; Neely 1999). Thus, by understanding how complexity evolves, organizations can support the process stages by developing best practices' in measuring and managing the performance (Bourne et al. 2000; Melnyk et al. 2014; Nudurupati et al. 2011).

Recently, a few studies have emerged to tackle complexity of PMSs in organizations. For instance, Melnyk et al. (2014) proposed a performance alignment matrix in an attempt to address complexity in the light of outcomes vs. solutions. Nudurupati et al. (2016) presented a case addressing complexity due to external organizational factors in digital economies, which is also echoed by Harkness and Bourne (2015) as well as Roehrich and Lewis (2014). Smith and Bititci (2017) identified social and technical controls to address complexity in organizations. Although the majority of these and past studies proposed better frameworks, technical controls and management controls, only a few studies adopted a theoretical stance for understanding the complexity of PMSs. It is therefore necessary to understand complexity and to investigate how it emerges in the stages of PMSs and how organizations can manage it. Therefore, the overall aim of this study is to understand the emergence of complexities while implementing and using PMSs in organizations. The purpose of this study is not to identify another list of social and technical (organizational) controls, but to identify PMSs as systems by understanding how their associated properties emerge from a complexity theory perspective. This study seeks to understand the complexity of PMSs before educating practitioners in choosing the right organizational controls to moderate a PMS's behaviour based on the context.

Pettigrew (1977, 2014, p. 134). views organizations as non-equilibrium systems and argues that understanding organizational change and political processes requires a systematic approach rather than a reductionist approach. However, implementing PMSs in organizations bring in change, so, for understanding this change in organizations, a complexity theoretical view becomes important (Ladyman et al. 2013). From a complexity theory perspective, four system properties were examined to understand complexity in a PMS: ontological, teleological, genetic and functional properties (Anderson 1999; Morel and Ramanujam 1999; von Bertalanffy 1969). These four system properties are closely associated with the two separate but interdependent dimensions, technical and social controls, identified by Smith and Bititci's (2017) theoretical framework. This framework is used as a basis for abstracting findings from this study.

To achieve the study's overall aim, data were gathered from secondary sources relying on a systematic 
literature review (SLR). The SLR method filtered studies to examine the latent practices used by different organizations in different operational contexts at three core process stages. The four system properties of complexity were then mapped onto the two types of controls that exist for implementing and using PMSs. The findings suggest that the performance measurement complexity (PMC) emerges in six forms,: namely, role, task, procedural, methodological, analytical and technical complexities that are mapped on to the two dimensions of organizational control theory, which is a significant contribution to the theoretical foundations of PMM literature. A major inference of understanding PMC is to refocus how organizations should systematically select from the multiple best practices by examining the unique context in which a PMS is operating. The study's findings also contribute to the current discussion on how PMSs should be responsive and resilient in emerging contexts (Bititci et al. 2012; Melnyk et al. 2014; Nudurupati et al. 2016).

The rest of the paper is organized as follows. The next section presents the background literature and complexity theory adopted from other fields (Briscoe et al. 2012; Geraldi et al. 2011). This informs the PMM literature regarding how PMSs can be viewed as complex systems. This is followed by presentation of the method employed in gathering, filtering and analysing the data. The study then presents the key findings obtained from the analysis, followed by a thorough discussion. Finally, a conclusion highlights a summary of the findings and key contributions, which is followed by the limitations of this study and future avenues of research.

\section{Background literature}

Although the PMM domain has received adequate attention from researchers and practitioners, most of the PMSs are still not dynamic and resilient to changes in the internal and external environment of the firm (Melnyk et al. 2014; Nudurupati et al. 2011). As a result, some of organizations operating in dynamic markets are addressing static PMSs while working on dynamic strategies, resulting in complexity and a lack of efficiency in resource allocation. To understand the dynamics of complexity in PMM, it is useful to understand the life cycle of PMSs, the technical and social controls for operating PMSs and the complexity theoretical lens through which PMSs are understood to be complex systems.

\section{PMM literature}

With the dissatisfaction in traditional backwardlooking financial accounting systems, a number of frameworks and models have been proposed (see Bititci et al. 2000; Neely et al. 2000). However, few scholars have explored aspects of implementing PMSs, and a three-phase model proposed by Bourne et al. (2000) has been widely accepted in the literature. The first phase is designing the performance measures, which are aligned with the organization's strategy. The second phase is implementing the measures by putting appropriate systems and procedures in place to collect and process data that allow measurements to be made. The third phase is ensuring that the measures are used as part of decision-making, while challenging the validity of measures on a regular basis. Since the establishment of this model, a number of researchers from different disciplines have worked in this domain to identify the best practices in these three phases under different contexts (Bititci et al. 2012; Bourne et al. 2003; Choong 2013; Deng et al. 2012; Folan and Browne 2005; Garengo et al. 2005; Jääskeläinen and Sillanpää 2013; Lohman et al. 2004; Mason-Jones and Towill 2000; Neely 2005; Nudurupati et al. 2011; Suprapto et al. 2009).

Recently, Bititci (2015, pp. 170-187) collated the majority of this work and synthesized it into two broad perspectives: social (art) and technical (science) controls. The social controls are posited to be the cultural and behavioural controls achieved through personal traits, structures or bureaucratic elements and interactions. Some of these controls may be implicit and informal. For instance, effective leadership can empower people and promote democratic and participative culture while using performance measures. The technical controls incorporate specific methodologies that are objective and rational and are employed to reach a specific goal. These are known to be scientific, objective and tend to be explicit in nature and include a variety of measures, information systems, data collection methods, analyses and visual communication (Bititci et al. 2000; Kennerley and Neely 2002).

In practice, when not used or implemented appropriately, these controls tend to amplify complexity during the process stages of PMSs (Bititci 2015, pp.170-187; Bititci et al. 2012; Kauppi 2013; Nudurupati et al. 2011; Pekkola and Ukko 2016), resulting in a significant misuse of resources. For example, while reinventing its PMS, Deloitte found that approximately two million hours a year were spent on 


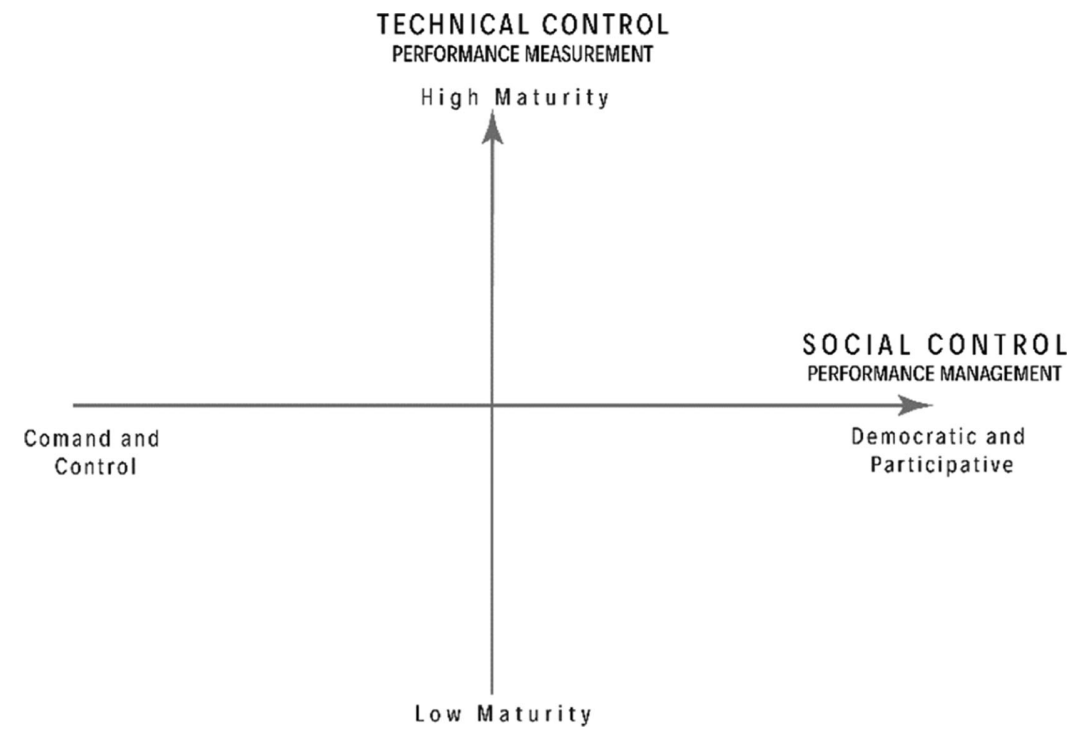

Figure 1. Framework that typifies social and technical controls (Smith and Bititci 2017)

the formalities of performance management (Buckingham and Goodall 2015). Smith and Bititci (2017) proposed a theoretical framework with the technical and social controls as two dimensions and identified a number of best practices for PMM, as depicted in Figure 1.

\section{Perspectives of complexity theory}

Complexity theory has evolved from systems theory, which emerged from natural sciences that examined randomly emergent non-linear interactions in a system (Burnes 2005; Grobman 2005). Grobman (2005) argues that complexity theory goes beyond systems thinking and can be applied to understanding the management and design of organizations. Complexity in an organization is usually triggered by change, whether small or large, and can have varied levels of consequences, even when the organizations consist of similar components (Burnes 2005). As discussed earlier, it is useful to explore further how the change triggers instability in organizations and how they can control that change. According to Bititci et al. (2012), contemporary organizations operate in turbulent environments in which change can be triggered from a number of sources, i.e. globalization, open innovation, autopoietic networks, technological disruption, social media, process re-engineering, continuous improvement and PM.

While the literature exploring complexity defines it in several ways, the following descriptions are most commonly used. First, Simon (1996) conceptualizes complexity through a hierarchical model, arguing that, when faced with a dilemma of many parts in the system, the system breaks down into subsystems until a lowest abstraction is reached. Second, Anderson (1999) extends complex adaptive systems by arguing that the strategic direction of a complex system consists of establishing and modifying environments within which effective, improvised, self-organized solutions can evolve. Based on these works, most attention has been focused on trying to determine all the interactions within the system, why they interact and how they interact. These interactions remain influential when studying complexity. Third, Edmonds (1999) proposes that complexity is the model property that makes formulating its overall behaviour in a given language difficult, even when given reasonably complete information about its atomic components and their inter-relations (Vidal and Marle 2008).

Sahin et al. (2013) defines complexity as a behaviour that emerges from the way the components of the system are interconnected, but not how the components of the system are themselves complex, although the components, people and/or firms are indeed as complex themselves because they are generally complex adaptive systems (Wilkinson 2006). Similarly, Stacey (1995) argues that organizations are made up of complex non-linear systems interacting with a number of their associated members, which will exhibit a pattern of behaviours. Introducing the understanding of complexity in a PMS would 
influence the existing systems and their associated agents to produce a new pattern of behaviours, which should be controlled for an effective outcome. Thus, in its most basic form, the concept of complexity suggests that, by understanding the structure and behaviour of each component within a system, the system as a whole could be understood with interrelations between several components (Anderson 1999; Galbraith 1982; Kandjani \& Bernus 2012).

According to Anderson (1999), a system has a number of interactions among its associated components and agents and with the environment in which it operates. Using the system perspective to characterize complexity is not new (Ladyman et al. 2013). For example, in understanding project complexity, a wide range of empirical studies uses the systems view to examine complexity (Geraldi et al. 2011; Vidal and Marle 2008). Similarly, by providing insights on procurement, a systemic complexity theory was applied (Roehrich and Lewis 2014). The system view means examining and categorizing the known system properties, ontological, teleological, genetic and functional, which are real world manifestations of a particular system. The ontological property represents the internal structures that include leadership, organizational culture and behavioural factors. The teleological property represents an object in an environment that aims to reach an objective. The genetic property represents the system's evolution over time. The functional property represents the focal activity to be performed (Boulding 1956; von Bertalanffy 1969).

\section{Complexity theoretical lens for characterizing complexity in PMM}

The PMM literature does not contain many studies that examine complexity explicitly in depth. However, a few researchers have studied the impact of complexity on PM (Bourne 2015; Harkness and Bourne 2015; McAdam and Bailie 2002; Neely et al. 2000). Neely (2005) explores the different ways in which managers can make strategic decisions under complex situations; he also proposes different approaches to organizational learning. Bititci et al. (2006) explore the complex nature of causal links between PM, management styles and organizational culture. In a similar vein, Bititci et al. (2012) argue that practitioners have to address complexity by rethinking the future of measurement, but they do not explain what exactly amplifies complexity. Braz et al. (2011) and McAdam and Bailie (2002) highlight complexity in their work, but they mostly dismiss it as a minor issue. There are number of factors that portray complexity as a potential barrier to PMSs' attaining efficacy (Bititci 2015, pp.170-187; Harkness and Bourne 2015; Paranjape et al. 2006; Sullivan 2011). The PMM literature also refers to complexity when it addresses the evolution of PMSs. For instance, Bititci et al. (2012) reveal business trends and how PMM is moving towards challenging operational contexts, thus suggesting that it is a self-learning system.

To understand the sources of complexity in PMSs, they must be considered complex systems, and the question of whether managing such systems exhibits system properties similar to those described in the literature must be explored (Ladyman et al. 2013; Morel and Ramanujam 1999). These goals are achieved by exploring the PMM literature for practices, processes, policies and mechanisms that are associated with the design, implementation and use process stages of PMSs that match the system properties as defined in the previous section. It is concluded that, by their definition and use, PMSs exhibit similar properties when viewed as systems, i.e. as discussed in general system theory (von Bertalanffy 1969). A PMS is treated as an entity operating in an environment (Vidal and Marle 2008) with its four system properties: ontological, teleological, genetic and functional. Table 1 shows the system properties that are the attributes of a PMS.

It is important to recognize that PMSs are complex adaptive social systems (Holland 1975), which means that they are systems in which users contribute to both creating and responding to their environment to achieve a goal. In this case, the goal is to monitor and measure performance in order to improve and control its components. The definition of complexity resonates with PMSs in that, even though there are several frameworks available to guide a PMS through its life cycle and explain exactly what organizations need to do, the system behaviour as a whole is unpredictable, owing to the complex nature of the organizational interactions that are further aggravated by social and technical controls (Miller and Friesen 1984).

The overall aim of this study is to understand the emergence of complexities while implementing and using PMSs in organizations. Therefore, the background literature has provided some insights on complexity theoretical perspective and identified four system properties that are closely associated with social and technical (organizational) controls (Smith and Bititci 2017) when implementing PMM. Most of the organizational controls identified in the literature are generic, although support PMM in 
Table 1. Complexity dimensions associated with PMMs

\begin{tabular}{ll}
\hline System property & Performance management system indicators \\
\hline Ontological & $\begin{array}{l}\text { The ontological property is internal structures such as the people component, varied staff, behavioural factors, } \\
\text { leadership styles, variety of information, diversity in practices, number of stakeholders, trust, and different views on } \\
\text { what to measure (Bititci et al. 2012; Nudurupati et al. 2016; Toor and Ogunlana 2010; Wijngaard et al. 2006) and } \\
\text { organization culture (Aguinis et al. 2011; Bititci et al. 2006; Elzinga et al. 2009; Ukko et al. 2007). }\end{array}$ \\
The teleological property specifies goals (Jääskeläinen and Laihonen 2013), objectives (Haponava and Al Jibouri \\
2009; Mol and Beeres 2005) and managerial practices (Angelis and Jordahl 2015). Stakeholder goals (Beer and \\
Micheli 2017). \\
The functional property considers need-specific methodologies and contingent factors (Lohman et al. 2004; Micheli \\
and Kennerley 2005; Micheli and Mari 2014; Nudurupati et al. 2011) as well as PMS frameworks (Ferreira and \\
Otley 2009). \\
The genetic property considers the time factor, evolution of measures (Mol and Beeres 2005), phases of product life \\
cycles, time factors (Caniato et al. 2014), maturity of key performance indicator, and continuous improvement \\
(Braz et al. 2011; Elg et al. 2013).
\end{tabular}

organizations. However, the purpose of this study is to explore the sources of complexity, so that specific organizational controls can be identified or developed to increase the usefulness of PMM. As PMM is a mature field with a number of empirical studies emerging every year, collecting evidence from extant literature is a good starting point for this study. Using the SLR approach, this study gathers more data from secondary sources to abstract sources of complexity when implementing and using PMM.

\section{Method}

An SLR approach was applied to identify and synthesize the most relevant academic literature in this field. Our work, Therefore, differs from traditional narrative reviews because it adopts a detailed, replicable and transparent scientific process that aims to minimize bias through exhaustive bibliographical searches of published studies (Cook et al. 1997; Davis et al. 1995; Moustaghfir 2008). An SLR approach provides useful guidelines that can be followed by other researchers in different fields (Cook et al. 1995; Petticrew and Robert 2006). The chronological evolution of the research on PMM is examined to see whether there is growing interest in academia and hence in the results presented on the chronological development of publications related to this subject. An SLR analysis allows researchers to focus on the purpose rather than on the utility of publications (Ginieis et al. 2012) and it provides a structured way to summarize various findings with minimum bias (Cook et al. 1997). This study adopted the guidelines proposed by Tranfield et al. (2003) and Moustaghfir (2008), and presents six stages, as demonstrated in Figure 2.

\section{Step-by-step process for sample selection}

Stage 1. The keywords words associated with PMM are identified from the background literature, scientific publications and the authors' previous experience in the field (Tasca et al. 2010). In line with the suggestion of Tranfield et al. (2003), more than one researcher participated in the decisions regarding keyword selection and their combination to generate effective search strings. Emphasis was placed on the degree to which the control factors interactively affect the process phases of a PMS throughout its life cycle as defined in the literature, the design phase (Deng et al. 2012; Lohman et al. 2004), the implementation phase (Bourne et al. 2003; Jääskeläinen and Sillanpää 2013; Suprapto et al. 2009) and the use phase, and as adopted by different organizations in different sectors (Bititci et al. 2012; Choong 2013; Folan and Browne 2005; Mason-Jones and Towill 2000; Neely 1999). Therefore, different performance-related strings are used as primary sources, which are concatenated with the secondary keywords 'design', 'implementation' or 'use':

1. 'performance management' AND use OR design OR implementation

2. 'performance measurement' AND use OR design OR implementation

3. 'performance assessment' AND use OR design OR implementation

4. 'performance indicators' AND use OR design OR implementation

5. 'performance appraisal' AND use OR design OR implementation

6. 'performance control' AND use OR design OR implementation 


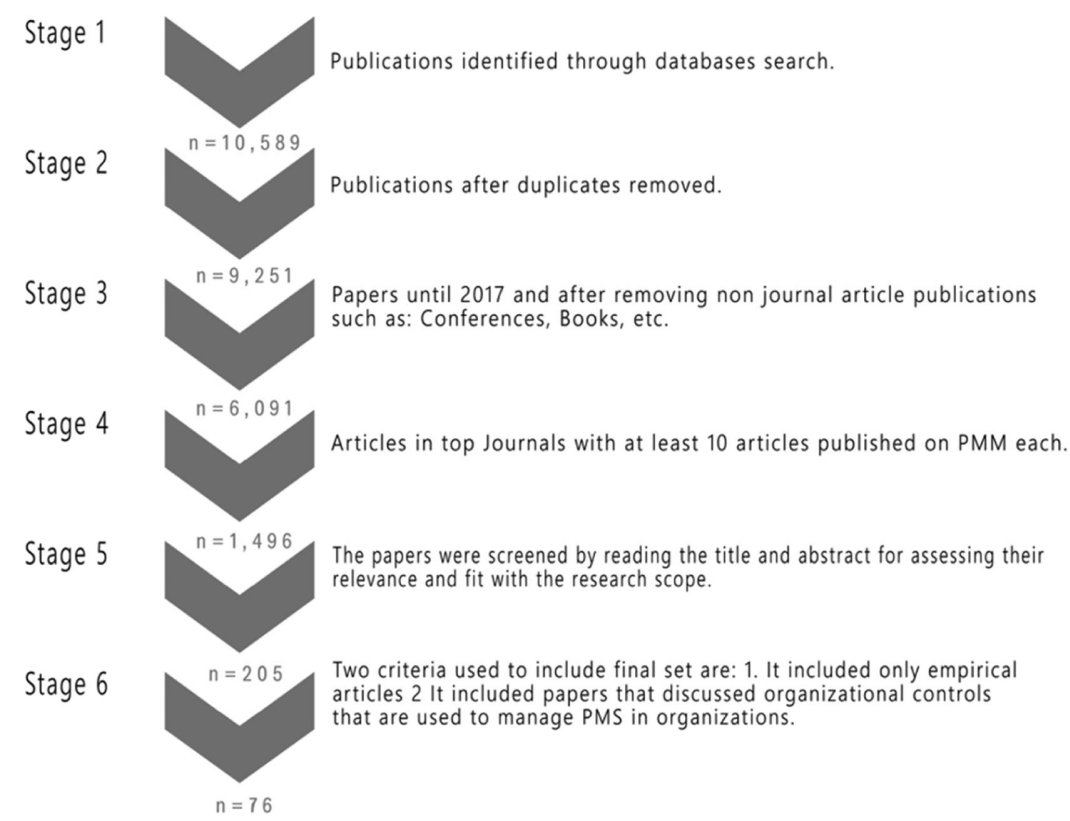

Figure 2. Step-by-step process for sample selection

7. 'performance complexity' AND use OR design OR implementation

8. 'performance strategy' AND use OR design OR implementation

9. 'supply chain performance' AND use OR design OR implementation

10. 'performance measurement system' AND use OR design OR implementation

11. 'performance management system' AND use OR design OR implementation

12. 'performance measurement and management' AND use OR design OR implementation

13. 'organisational performance' AND use OR design OR implementation

14. 'organizational performance' AND use OR design OR implementation

To perform the keyword search, the databases Web of Science (WOS) from Thomson Reuters and Scopus from Elsevier were used, because they provide a wide coverage of areas within this discipline and provide different searching, browsing and filtering options (Ginieis et al. 2012; López-Illescas et al. 2008). These keyword combinations are searched in the title, keywords and/or abstract of the paper. Table 2 presents the number of articles published in different journals in chronological order.

Stage 2. As demonstrated in Figure 2, the initial keyword combination search yielded 10,589 outputs in the previous stage, which were further filtered in this and subsequent stages in a process that incorporates the exclusion criteria established by the research protocol (Jones and Gatrell 2014). The use of two databases resulted in duplicates, which were removed in Stage 2, resulting in 9251 outputs. As demonstrated in Figure 3, until the late 1990s, only 952 publications of PMM (only $10 \%$ of total of studies analysed) had been published. The noteworthy increase in publications in this field has been observed since the beginning of the year 2000. More specifically during the period 2000-2008, 2213 documents were published (24\%). Finally, it is important to remark that, in the last few years (2009-2017), 6086 studies on PMM $(66 \%)$ have been published. This demonstrates the growing importance that this topic has had in the academic literature in recent years. This is one of the fundamental reasons why this study adopted an SLR approach.

Stage 3. The papers were further filtered to include only peer-reviewed journal articles, which reduced the number to 6091 articles. For instance, Table 2 presents the number of articles retrieved using different keyword search strings in chronological order.

Stage 4. Articles were further filtered by specific journals listed in the categories Management/Business (WOS), Business, Management and 
Table 2. Keyword analysis and articles until 2017

\begin{tabular}{|c|c|c|c|c|c|c|c|c|c|c|c|c|c|c|}
\hline Keywords & Until 2005 & 2006 & 2007 & 2008 & 2009 & 2010 & 2011 & 2012 & 2013 & 2014 & 2015 & 2016 & 2017 & Total \\
\hline performance management & 79 & 16 & 22 & 19 & 32 & 28 & 34 & 40 & 37 & 44 & 65 & 65 & 48 & 529 \\
\hline performance measurement & 313 & 41 & 58 & 66 & 70 & 77 & 63 & 67 & 61 & 90 & 108 & 102 & 99 & 1215 \\
\hline $\begin{array}{l}\text { performance appraisal; } \\
\text { performance control; } \\
\text { performance complexity; } \\
\text { performance strategy; } \\
\text { supply chain performance; } \\
\text { performance measurement } \\
\text { system; performance } \\
\text { management system; } \\
\text { performance measurement } \\
\text { and management; } \\
\text { organisational } \\
\text { performance; } \\
\text { organizational performance }\end{array}$ & 308 & 36 & 46 & 50 & 65 & 81 & 81 & 90 & 81 & 96 & 122 & 153 & 155 & 1364 \\
\hline $\begin{array}{l}\text { performance assessment; } \\
\text { performance indicators }\end{array}$ & 595 & 80 & 104 & 112 & 127 & 156 & 154 & 213 & 213 & 238 & 305 & 332 & 354 & 2983 \\
\hline Total & 1295 & 173 & 230 & 247 & 294 & 342 & 332 & 410 & 392 & 468 & 600 & 652 & 656 & 6091 \\
\hline
\end{tabular}

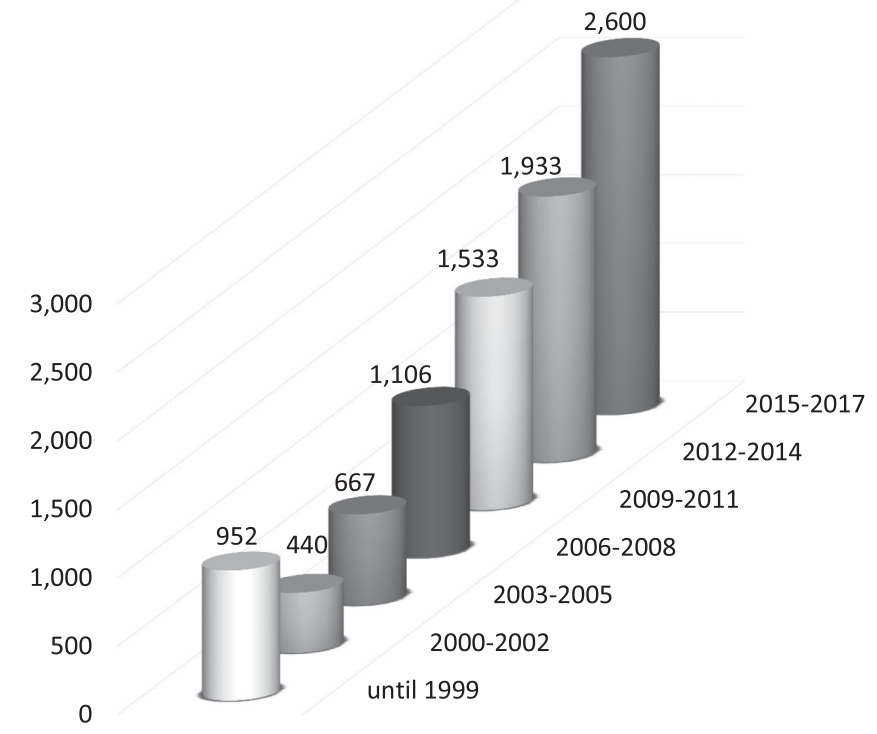

Figure 3. Number of publications on PMM to 2017

Accounting (Scopus), Operations and Technology Management, General Management, Ethics and Social Responsibility. With the increase in the number of journals emerging every year, it is becoming difficult to judge the quality of papers. Therefore, the Chartered Association of Business School (ABS) journal ranking guide and the Australian Business Deans Council (ABDC) journal quality list were used to filter the articles further. All journals (irrespective of their rank or rating) listed in these guide were used to filter the list. Using this search strategy in these databases and guides, the study intends to locate the academic journals most recognized by the scientific community in the different fields of knowledge. Furthermore, this filtering ensures that a high standard is maintained in the performance of the SLR and in its output. Similarly, McGovern (2014) conducted a systematic review based on only four leading academic journals. He justified this decision by noting that all four journals were 'considered to be leading journals and, as such, might reasonably be expected to exert some influence over their respective subfields' 
Table 3. Evolution of the number of PMM publications in journals WOS/Scopus/ABS/ABDC

\begin{tabular}{|c|c|c|c|c|c|c|c|c|c|}
\hline Journal & Until 2010 & 2011 & 2012 & 2013 & 2014 & 2015 & 2016 & 2017 & Total \\
\hline International Journal of Operations \& Production Management & 53 & 6 & 2 & 2 & 4 & - & 3 & 4 & 74 \\
\hline Energy and Buildings & 7 & 4 & 4 & 5 & 3 & 5 & 8 & 8 & 44 \\
\hline International Journal of Human Resource Management & 21 & 6 & 2 & 3 & 3 & 2 & 2 & 5 & 44 \\
\hline Journal of Cleaner Production & 8 & - & 2 & 1 & 1 & 7 & 9 & 14 & 42 \\
\hline International Journal of Production Research & 18 & - & 1 & 2 & 3 & 8 & 5 & 4 & 41 \\
\hline Public Performance \& Management Review & 7 & 11 & 4 & 3 & 2 & 7 & 5 & 2 & 41 \\
\hline International Journal of Production Economics & 21 & 3 & 2 & 2 & 3 & 5 & 2 & - & 38 \\
\hline Energy Conversion and Management & 5 & 1 & - & 4 & 5 & 7 & 8 & 4 & 34 \\
\hline Reliability Engineering \& System Safety & 22 & - & 2 & - & 7 & 1 & 1 & 1 & 34 \\
\hline Production Planning \& Control & 15 & - & - & 4 & 7 & 2 & 2 & 3 & 33 \\
\hline Total Quality Management \& Business Excellence & 21 & 1 & 2 & 1 & 2 & - & 2 & 3 & 32 \\
\hline Expert Systems with Applications & 15 & 6 & 2 & - & 4 & 2 & 1 & - & 30 \\
\hline Industrial Management \& Data Systems & 19 & 1 & 3 & 2 & 1 & - & - & 3 & 29 \\
\hline Public Administration Review & 18 & - & 1 & 3 & - & 2 & 4 & 1 & 29 \\
\hline International Journal of Productivity and Performance Management & - & - & - & - & - & 11 & 8 & 9 & 28 \\
\hline Journal of Business Research & 15 & 1 & 1 & 2 & 2 & 3 & 4 & - & 28 \\
\hline Applied Thermal Engineering & 4 & - & 1 & 2 & 2 & 4 & 7 & 6 & 26 \\
\hline Other Journals & 384 & 58 & 62 & 64 & 61 & 80 & 76 & 84 & 869 \\
\hline Total & 653 & 98 & 91 & 100 & 110 & 146 & 147 & 151 & 1496 \\
\hline
\end{tabular}

(McGovern 2014, p. 23). This SLR followed a similar path and was organized to consider only journals relevant to this discipline and that have published at least ten articles on PMM. This resulted in 1496 articles. The initial data analysis of 1496 articles revealed some useful information that shed light on the research trends and direction. For instance, Table 3 presents the journals that have published most articles on PMS in chronological order.

Stage 5. The papers were screened by reading the title and abstract to assess their relevance and fit with the research scope, which resulted in 205 papers. Similar steps have been employed in previous SLRs (Bonatto et al. 2015; McGovern 2014; Tasca et al. 2010; Turner et al. 2013). Where an abstract is not clear, it is included for full appraisal.

Stage 6. It is an iterative process at this stage, where the 205 papers are fully appraised to assess their suitability to this study using filtering criteria. First, the study included only empirical articles where the observations are grounded in practice. Second, the focus of this study is the exploration of sources of complexity while implementing and using a PMS. Therefore, from the outset, complexity can be understood to be a result of the conflict between organizational practices and mechanisms with social and technical controls associated with PMSs. This stage therefore included papers that discuss organizational controls that are used to manage PMS in organizations. Finally, a total of 76 papers were thoroughly analysed and evaluated. These papers were further supplemented by additional papers obtained through citation tracking together with the authors' previous experience where appropriate. The selected papers from the SLR covered a wide range of aspects, such as human resources, manufacturing, measurement systems in small and medium-sized enterprises (SMEs), financial and non-financial operations, leaderships styles and motivation at work associated with PMSs.

Data analysis. The data obtained from these multiple sources were synthesized, and the key research findings were abstracted. Multiple sources were examined for common patterns. The explanations obtained from the triangulation of consistent patterns, comparable meanings or common aims were integrated into themes. The synthesis, pattern-matching and integration promoted the development of six theoretical presentations of complexity, which are further presented in the findings section. While the authors emphasized triangulation, the identification of common patterns and the development of integrated explanations, they did not attempt to quantify any occurrences for use in the analysis. The papers appraised were grouped by the author(s), purpose, research method adopted, PMS life cycle stages explored and, finally, the understanding of the type of complexity abstracted in each study (see Table 4). To identify the emerging complexity, the authors 


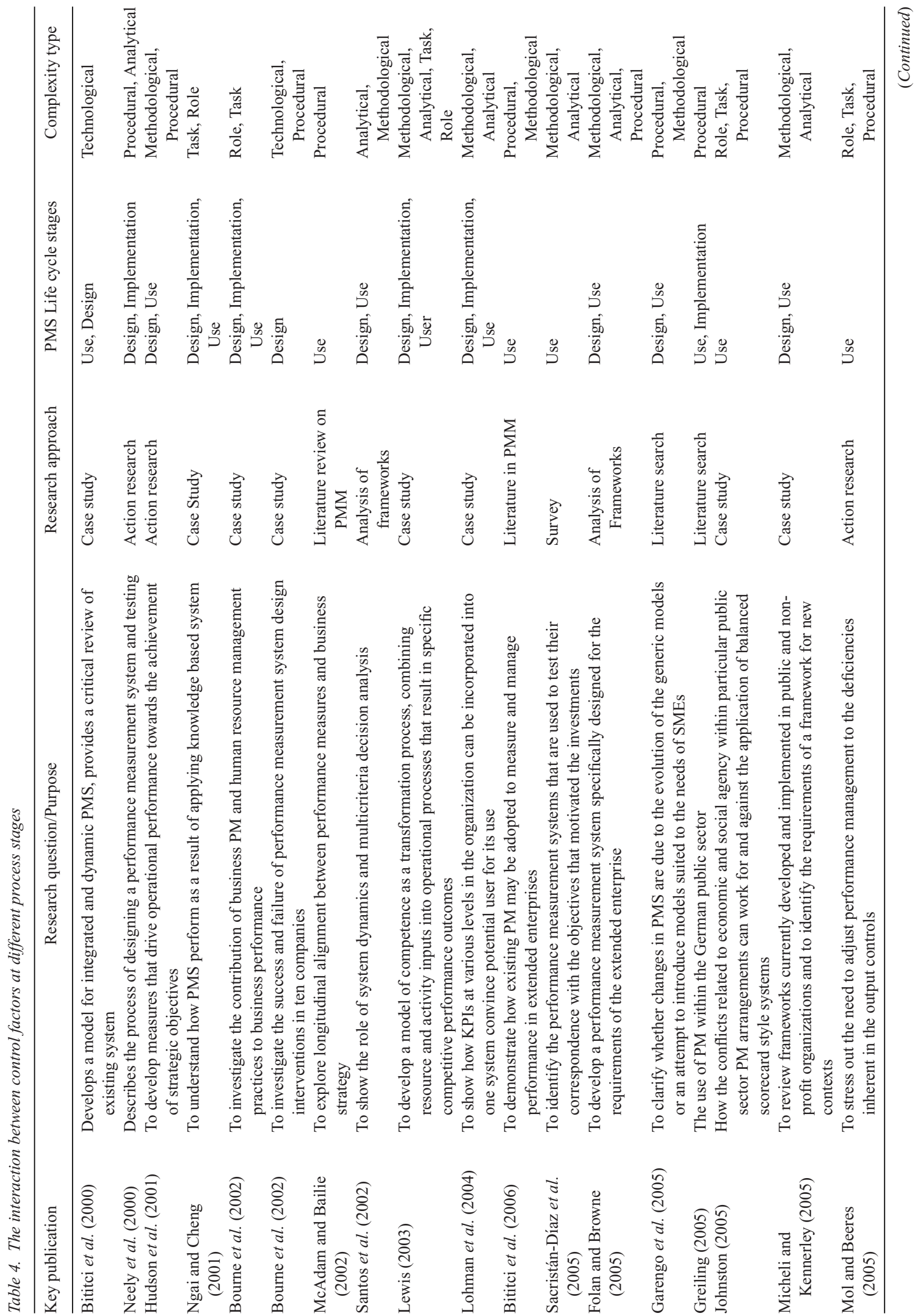




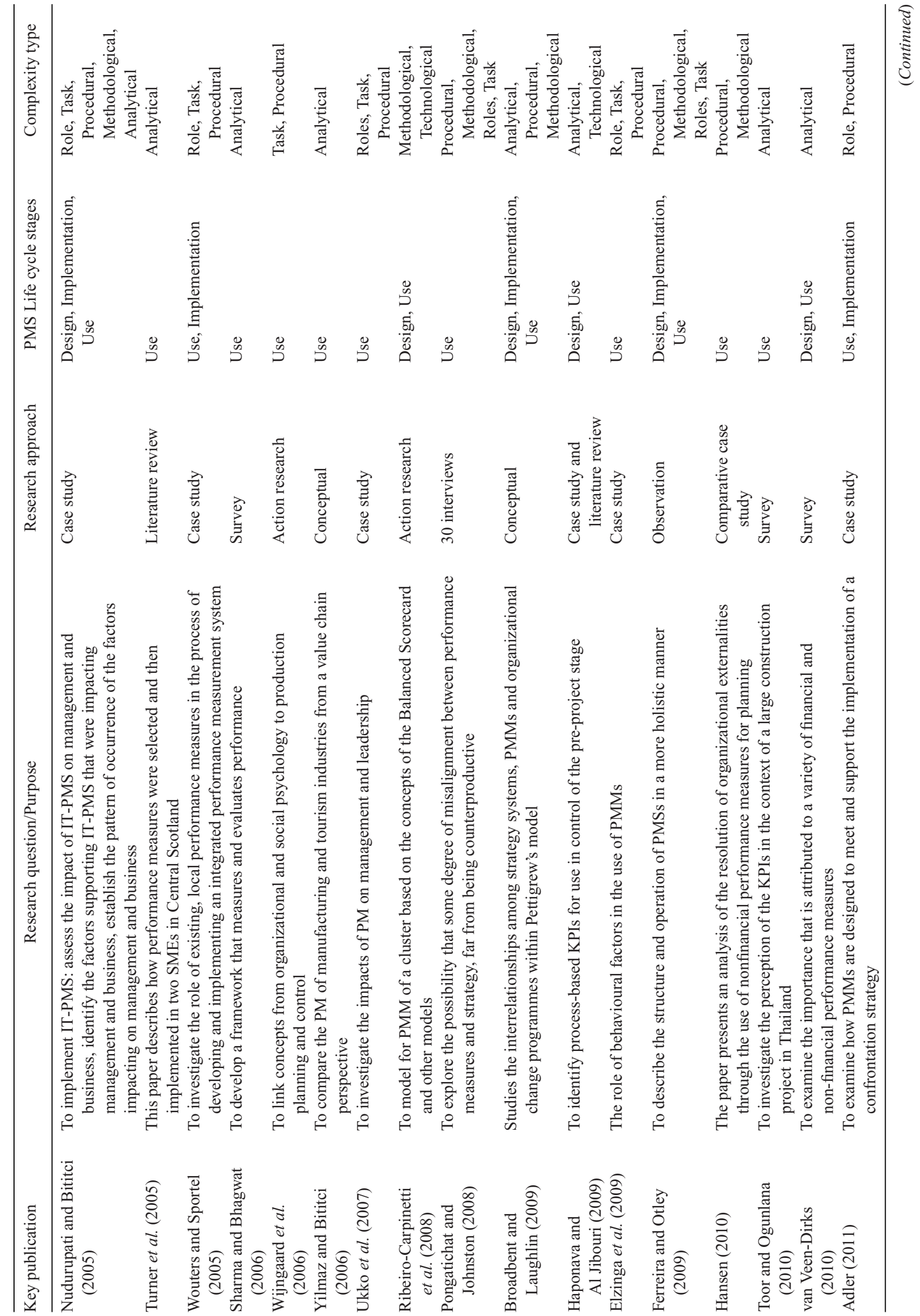




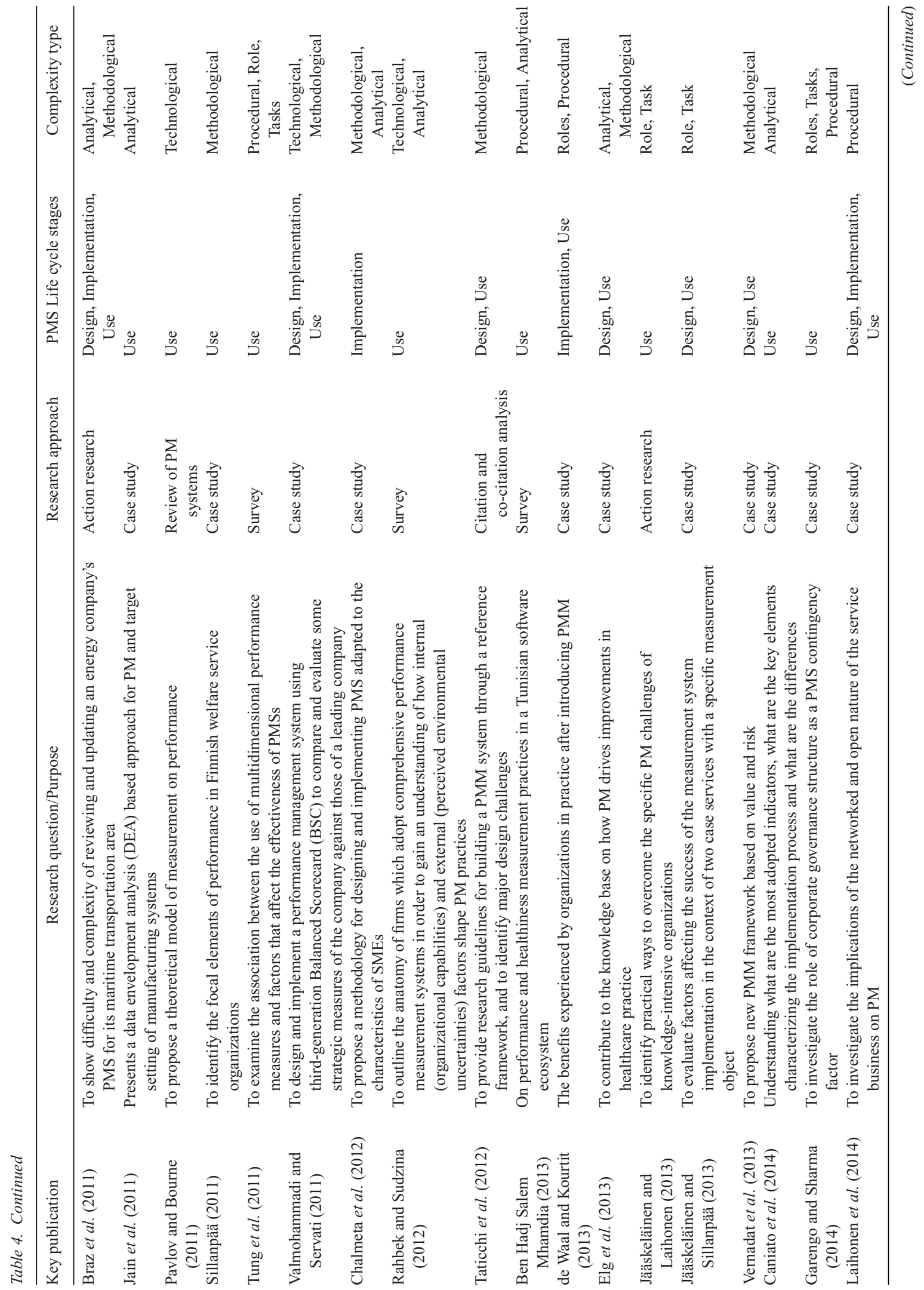




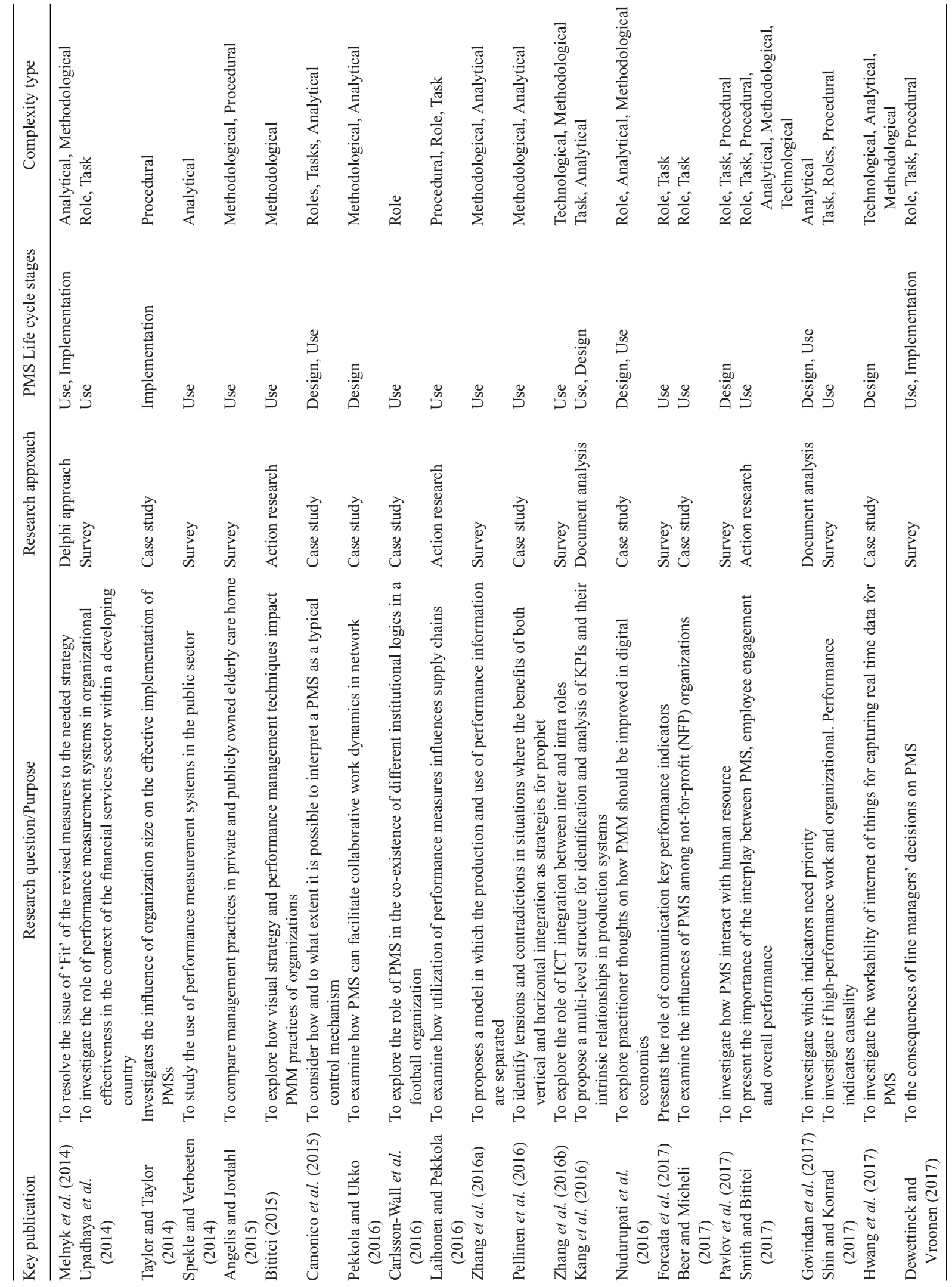




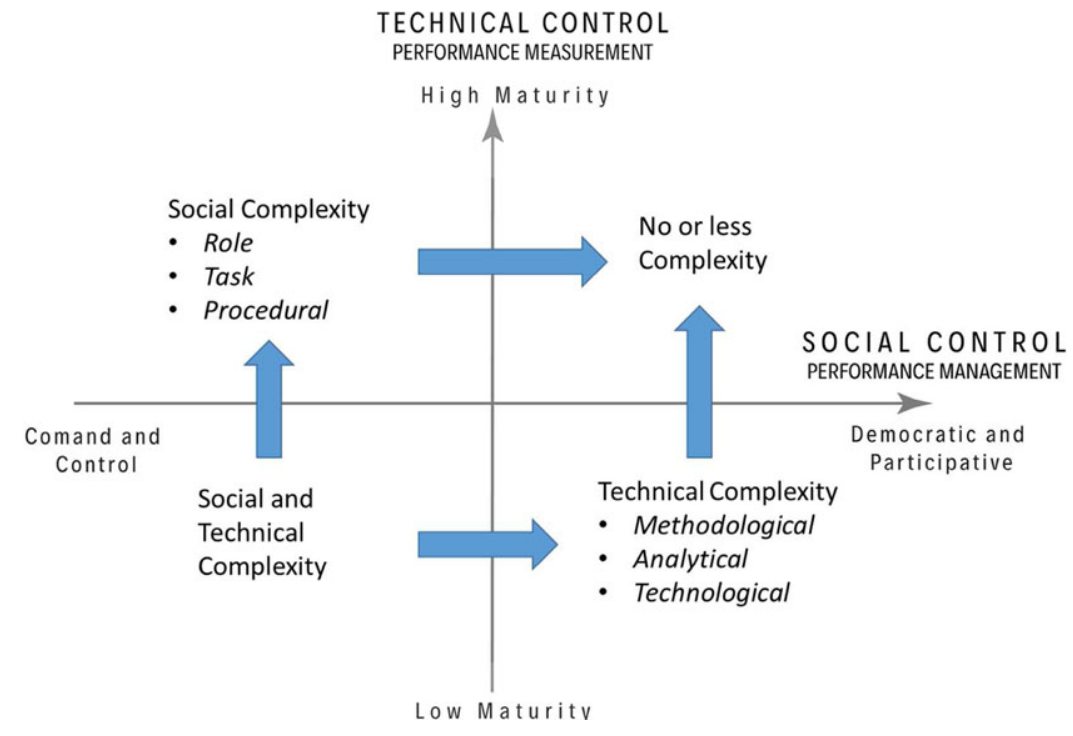

Figure 4. Sources of complexity in PMM dimensions (Adapted from Smith and Bititci 2017) [Colour figure can be viewed at wileyonlinelibrary.com]

independently reviewed each of the manuscripts with the four system properties described in Table 1 in the light of social and technical controls.

\section{Key findings}

The findings reveal that most of the studies identified either social or technical controls as a foundation for an effective PMS. For example, after analysing 76 empirical studies, Franco-Santos et al. (2012) classified unique contemporary PM features into three categories: people's behaviour, organizational capabilities and performance consequences. They highlighted the necessity of understanding how organizations respond to dynamic situations. Similarly, Braz et al. (2011) studied the process of reviewing and updating a company's existing PMS to reflect changes in the environment. They identified that PMS users, assessing of performance indicators and the establishment of goals are key. Many other researchers indicated that supporting frameworks, information systems, data-collection methods, analysis and visual communication were technical controls for effective PMSs. However, none of these studies had a critical view of the complexity theoretical lens. Therefore, this study aims to understand the emergence of complexities while implementing and using PMSs in organizations. Smith and Bititci's (2017) theoretical framework identified social and technical controls to assess the maturity of PMM in organizations using an organizational theory perspective. This study identified six sources of complexity that are closely associated with the social and technical dimensions of Smith and Bititci's (2017) framework and used it as a reference model. As demonstrated in Figure 4 , six sources of complexity were abstracted from this study: role, task and procedural types of complexity were associated with social dimension, while methodological, analytical and technological types of complexity were associated with technical dimension.

\section{Social complexity}

The SLR analysis abstracted the first theme, social complexity, which is associated with leadership, hierarchical structures, empowerment, trust, motivation at work, employee behaviour, training, skills, trust and culture. These characteristics closely match the ontological property of complexity. With the evolution of a PMS, some of these social controls improve and become more fine-tuned and mature, thus connecting to the genetic property of complexity. Most of the studies that explored social controls identified them as foundational for PMSs at every process stage. For example, Elzinga et al. (2009) set out to identify factors that influence the use stage of PMSs and argue that behavioural factors in different roles within an organization are the most important factors at the use stage of a PMS. In another study (Shin and Konrad 2017) on human resource management, social controls were also identified as high-performance work 
practices (HPWS), high involvement practices that help organizations to achieve a better performance.

Role complexity. According to command and control theory, organizations are established on the basis of hierarchical relationships with a clear flow of authority, to allow their entities to achieve economic performance and goals (Rizzo et al. 1970). When a PMS with a democratic culture is adapted to an organization, it can lead to conflict, incompatibility and ambiguity regarding existing roles, thus creating role complexity. From a theoretical perspective, if organizations do not control behavioural factors such as empowerment, autonomy, trust, communication and training, role complexity could develop. From the analysis, role complexity can be further explained as the relationship/conflict between different team roles and individual roles and how they should be appropriately allocated. Toor and Ogunlana (2010) highlighted the complexity of social controls in the construction industry. They revealed the differing perceptions on a construction project, leading to conflicting requirements regarding what to measure. Furthermore, in another study, Beer and Micheli (2017) gave a contribution on how performance management influences the attention and actions at an individual micro level, which also reveals social controls at an individual level.

Task complexity. Organizations establish the knowledge, skills and resources needed for an entity to demonstrate satisfactory performance (Wood 1986). Therefore, a task in an organization must be clearly defined; without this definition, there is often substantial ambiguity and conflict, leading to task complexity. From our sample, this is also echoed by Adler (2011), who argued that clarity regarding a task and task efficiency are particularly essential to organizations that are trying to be price minimizers or cost leaders. However, the introduction of new measures or new ways of measuring and managing often bring ambiguity and conflict with existing knowledge, skills and resources, thus leading to task complexity. Task complexity emerges not only from a lack of clarity on tasks, but also from inter-relationships and the conflicts between them; Therefore, it is necessary to explore mature social controls associated with task complexity. Adler (2011) studied the design of PMSs for confrontation strategies and found that programmes that focus on developing empowered, multi-skilled teams of self-governing and well-coordinated individuals lead to task efficiency.
Procedural complexity. While many authors (Bititci 2015, pp.170-187; Smith and Bititci 2017) acknowledge the need for social controls for an effective PMS, there is little consensus regarding how to strike the proper balance between the level of control over individuals and the level of freedom or autonomy given to them. While organizations have a number of rules to control the way they operate, introduction of a PMS will initiate turbulence and will create substantial ambiguity and conflict. Procedural complexity emerges when there is a lack of information regarding priorities or the course of action when there is a change in the routine. This complexity occurs when the new processes and their impact are not explained to employees. With mature social controls such as autonomy, empowerment, communication and multiskills (the benefits of PMS), organizations can selforganize and adapt to this change while also creating new rules, regulations and policies for operating an effective PMS, without which procedural complexity would develop. Social controls were also mainly identified in the study by Dewettinck and Vroonen (2017): drawing from signalling theory, theory of planned behaviour and social exchange theory, they investigated social controls such as attitudes, employee concern, job satisfaction and engagement. It was found that the antecedents and the outcomes of front-line management's enactment of performance management activities were moderated by managers' span of control.

\section{Technical complexity}

The analysis from the SLR abstracted the second theme, technical complexity, which is associated with frameworks or models, information systems, data collection methods, analysis and visual communication. These characteristics are closely associated with the functional and teleological properties of complexity. The teleological property represents an objective of the system, while the functional property represents the methods of achieving that objective. With the evolution of PMSs, some of these technical controls improve and mature, thus mapping onto the genetic property of complexity. Technical controls are formal and more explicit than social controls. Performance management systems have a specific goals, such as improving performance, learning or control and, Therefore, they use specific methodologies, technology and analyses to reach these goals (Bititci 2015, pp.170-187). 
Methodological complexity. When PMSs are implemented in organizations, there is often conflict between their objectives and associated measures. In most of these cases, organizations are less informed regarding which method should be used in choosing measures (often using subjective measures) and which philosophy to use in selecting the type of measures (often using objective measures). These situations usually lead to methodological complexity. Methodological complexity often relates to a conflict between an approach to choosing measures (such as quantitative vs. qualitative) and the difficulty encountered in selecting the type of key performance indicators (KPIs), their calculations and the number of KPIs to be used. Santos et al. (2002) investigated how system dynamics and multicriteria decision analysis can enhance the effectiveness of selecting measures during the design and implementation of a PMS while taking input from all stakeholders. From their findings, they recommended that the use of such approaches provides a means for addressing methodological complexity in organizations.

Analytical complexity. When implementing PMSs in organizations, there is often difficulty in understanding each measure, its influence on other measures, and its impact on the organization's strategy as a whole. These relationships are often undermined in organizations, leading to analytical complexity (Suwingnjo et al. 2000) Analytical complexity is often associated with a lack of understanding regarding cause and effect relationships between measures, data presentation, sophisticated charts and graphs, and visual screens. Therefore, organizations should use more scientific and objective methods such as mathematical and simulation modelling, systems dynamics, cause and effect analysis, correlations and regression for designing and using specific measures. These analytical approaches restrict subjectivity, ambiguity and conflict between measures (Santos et al. 2002). While studying the use of PMSs in the public sector, Spekle and Verbeeten (2014) identified technical controls, such as contractibility, clarity of goals and undistorted performance metrics, that create performance effectiveness. In another study by Hwang et al. (2017), the workability of the internet of things (IoT) for capturing real-time data was investigated: technical controls such as simulation results, planned and actual production data, timestamp data acquired by IoT were identified leading to analytical complexity. In an attempt to improve supply chain performance in another study (Govindan et al. 2017), technical controls such as collaborations and information exchanges, customer relationship management competitiveness, organizational-level innovation and supply chain reliability were found to using fuzzy AHP method for analysis, which is purely technical control leading analytical complexity.

Technological complexity. The way in which we are operating in digital economies is changing with the advent of technological developments (Nudurupati et al. 2016). While the way customers are engaging with businesses is changing, the way in which organizations are gathering data using advanced technologies is also evolving. The implementation of a PMS in this context is no exception, and organizations' failure to use technology appropriately leads to technological complexity. Technological complexity often emerges when there is no effective coordination and tighter integration between the selection of and investment in technology such as IT systems and the needs of the business. Turner et al. (2005) examined the implementation of performance measures and recommended that PMSs could enhance business performance if the implementation is well structured, resourced and focused on improving the capability of technical controls. In another study, technical controls such as measurement frameworks, information systems and reporting mechanisms using balance scorecards took greater precedence (Lohman et al. 2004).

\section{Discussion on PMC}

From a complexity theory perspective, a PMS is considered a complex adaptive social system (because it consists of a large number of elements whose interactions create new behaviours that cannot be predicted by a complete analysis of the individual elements (Sahin et al. 2013). A PMS has its own life cycle, and it interacts with a number of other elements exemplifying the levels of complexity at different times. Therefore, coercively controlling such an adaptive system can have a negative impact on the process of measurement and management (Bititci 2015, pp.170-187). However, the SLR reveals abundant literature arguing the need for different factors, controls and best practices to measure and manage performance. Overall, the analysis from the SLR suggests that complexity exists in a PMS through its life cycle, but varies based on how many combinations of organizational controls and elements interact with it. At one extreme, an overly controlled 
process can leave individuals unable to cope with a complex situation owing to rigidity. On the other extreme, if individuals are not given enough guidance (or too much autonomy) to measure and manage performance, the process may be adversely affected owing to variability.

Adler (2011) found that both technical and social controls were necessary to address the implementation of a confrontational strategy. The technical controls included strategies for cost leadership, differentiation and confrontation. The social controls included training, development, multiskilling and collective responsibility. In studying the advantages and disadvantages of using PMM tools and techniques, de Waal and Kourtit (2013) identified two main reasons for their use, which focused on controls and strategy. They recommended that management needs to take the explicit advantage of PMM when designing a PMS, and they stressed the advantages of social controls during and after implementation. However, in another study, Sharma and Bhagwat (2006) explored PMS implementation at both small and large firms. They presented a framework that suggests information systems as a foundation for growth and a way to drive strategy. The study focused on technical control factors and neglected to address the influence of social factors. While Smith and Bititci (2017) broadly divided most of these controls under the classification of technical and social controls, striking a balance between the two is important to mitigate complexity. Performance measurement complexity is a type of complexity that emerges internally, breeds within and through the short- and long-term routines of managing PMS and sustains unnoticed. Therefore, it is necessary to understand systematically how PMC emerges to identify its root causes before prescribing a solution. As demonstrated in Figure 4, the goal of an organization is to mitigate PMC by striking the right mixture and balance of technical and social controls to move into the top right quadrant of the theoretical framework.

Although it is widely accepted that complexity is a result of several external influences and factors that affect the organization and the PMS, this study has demonstrated that complexity is generated through the interaction of PMSs with several internal elements during its evolution. Harkness and Bourne (2015) identified internal factors such as ambiguity, a lack of control, unpredictability and information issues, which interact with PMSs as a precursor to complexity. Furthermore, research into PMM has been limited to the interplay between what is measured
(Micheli and Mari 2014) and how it is controlled (Canonico et al. 2015; Mol and Beeres 2005) and the process of updating, analysing, and acting on performance data (Bititci 2015, pp. 170-187; Bourne et al. 2000; McAdam and Bailie 2002). Hence understanding complexity from its ontological, functional, teleological and genetic properties will identify new dimensions in moderating complexity in PMM. From this perspective, this study identified six sources of complexity using a theoretical framework from complexity theory in the context of PMM. As discussed earlier, complexity may emerge in varying forms and in varying intensities at different stages of a PMS, depending on the context.

While studying the state-of-the-art of PM, Greiling (2005) suggests that, in order to keep the motivation and participation rate high with a PMS, it is necessary to concentrate on a few relevant indicators and that measurement for measurement's sake is not a goal in itself. Therefore, motivation acts as an important social control, particularly during the use stage of a PMS. A lack of motivation in employees can lead to role complexity, as they do not perform their jobs effectively. This role complexity is also exemplified by conflicting interests, different ambitions and different measures of success. Similarly, several studies have recognized that a lack of standardization generates task and procedural complexity (Jääskeläinen and Sillanpää 2013; Nudurupati and Bititci 2005; Ukko et al. 2007). While the three complexities discussed in the previous section, i.e. role, task and procedural, appear to be technical at first, the maturity of social controls such as motivation, leadership, training and skills, empowerment, self-regulation, trust and hierarchy plays a significant role in addressing the ontological property of PMSs, thus moderating social complexities. Ukko et al. (2007) found that it was the role of leadership skills and the manager's commitment as social controls that were crucial in aligning the manager's and employees' perspectives on the strategy and improving performance.

When measures are selected with lack of clarity or are poorly and ambiguously defined at the design stage, they may not reflect the strategy of the organization at the use stage, resulting in a complex situation (Courty and Marschke 2003). Kelman and Friedman (2009) argue that resources are usually deployed for actions related to improving measures while neglecting other aspects of the business, which eventually manifests in a vague complex situation. Nudurupati et al. (2016) argue that a lack of strategic intent in resource allocation for a PMS may create a 
technological mismatch with the business needs and result in a complex situation. The teleological and functional properties associated with such PMSs may be affected, leading to methodological, analytical or technological complexities. Mature technical controls such as a balanced set of metrics, a high degree of defined casual relationships, strategic measures deployed to lower levels, targets and incentives linked to strategic objectives, measures and their trends reported in an accessible manner, and regular and frequent performance reviews play a significant role in moderating technical complexities.

From complexity theory, the genetic property of a PMS represents how it evolves over time. From the SLR and its analysis, the genetic property is more associated with exploring the maturity and validity of KPIs over time. This property also incorporates the interaction of PMSs with other elements such as continuous improvement, changing programmes and external fluctuations that influence the organization. For example, Angelis and Jordahl (2015) studied the maturity of various performance management practices at the use stage, which maintains the evolution of the system. As a PMS matures, it provides standard management practices; however, as Kennerley and Neely (2002) state, 'measurement systems should be dynamic; they have to be modified as times change'. In this study, the authors examined the factors that affect the evolution of PMSs over time, including both social and technical controls, which are both internal and external to the system. The interaction of the continuous improvement framework for PMSs was studied at the design stage (Hudson et al. 2001). Similarly, Garengo et al. (2005) presented a model of how PMSs evolve over time. This study also explored all three process stages and found that 'the models developed in the last 20 years are more horizontal, process-oriented and focus on stakeholder needs'. This demonstrates and validates the genetic property of PMSs, and understanding this property is vital to their success. Similarly, the business trends in the external context also influence organizational strategy, leading to the need for change in the PMS over time (Bititci et al. 2012; Melnyk et al. 2014). Therefore, the moderation of complexity that stems from a PMS is not a linear task and needs to be controlled over time with feedback loops.

From the findings, social controls employed in PMS also appear to create a versatile condition for adapting technical controls. Managing PMSs is largely socially constructed rather than technically constructed and operated (Johnston 2005, p. 514).
Social controls are assumed to be purely concerned with the human aspects, such as group dynamics, relationships, commitment, leadership, authenticity, behaviours, values and trust. Therefore, as more organizations become democratic, the focus of control should shift from command and control to something more participative (Bititci et al. 2012; Bourne et al. 2000; Mol and Beeres 2005). Then, through democratic freedom, a new way of thinking can be encouraged among the employees.

This study attempted to shed light on the reasons why PMSs become successful in some organizations while failing in others, even if they consist of similar components. Therefore, changes to these organizational controls and their interaction with PMSs and other elements will give rise to new and unpredictable behaviours. This signals that the system is exhibiting complex properties that are unique and grow organically in that particular context, which ultimately requires unique monitoring and control. The lack of predictability of the usefulness of organizational controls also may exhibit unintended complexity.

\section{Conclusion}

The key motivation for this study was the PPM literature's attribution of a majority of complexity issues to the external environment while neglecting internal environmental perspectives. The purpose of this study is to identify the PMS as a system by understanding how its associated properties emerge from a complexity theory perspective. The study focuses on understanding the complexity of a PMS over its life cycle in order to shed light on moderating its behaviour. From the background literature, this study presented the PMM literature, which is dominated by organizational controls and best practices regarding what to measure, how to control and how to manage the process of updating, analysing and acting on performance. The study also explored how social and technical controls amplify complexity at the three core PMS process stages, and it presented new perspectives of complexity theory, i.e. the ontological, teleological, functional and genetic characteristics of a PMS.

Through a review of 76 PMM papers, the study described how complexity reproduces in a PMS over its life cycle. More specifically, the study showed that PMSs consist of a large number of interconnected and interdependent elements, which evolve over time and adapt to changes in the internal environment, making 
them a complex social adaptive system. Changes in the internal environment such as plurality in practices may negatively impact the PMS process, the number of controls that interact at each process stage, and the nature of these interactions. This makes it difficult to predict what will be important to measure in the future and how to measure and manage it. There is greater unpredictability and ambiguity in the system, often lacking the relevant information for decisionmaking. The results seem to emulate the issues of fit, as shown by Melnyk et al. (2014), in which the organization's measures are not synchronized with its strategy and its environment, leading to a complex situation. Therefore, organizations require more tools and techniques to survive complex situations.

The four characteristics identified in the study were used in examining the PMM literature and resulted in six forms of complexity, namely, role, task, procedural, methodological, analytical and technical complexities, which is a significant contribution to theory. A major implication of understanding PMC is to recast how organizations should systematically respond to the plurality of best practices by examining the unique context in which a PMS is operating. The study findings contribute to the current discussion addressing why PMSs typically lag and are not responsive and resilient in emerging contexts (Bititci et al. 2012; Melnyk et al. 2014; Nudurupati et al. 2016). While it is useful to understand and explore all organizational controls in moderating PMC, the organizational controls may have varying impacts on organizations even when they consist of similar components and are operating in the same industry. Using the insights from this paper, organizations should build the capabilities to choose the appropriate organizational controls, depending on the context and should adapt to the changes associated with PMSs.

This study sets new directions for PMM researchers and practitioners, as it identifies sources of complexity that will be complementary in prescribing social and technical controls in organizations for mitigating complexity. This study opens several avenues for future research on PMS complexity as well as on PMM in general. First, the definition of PMC, as outlined in this paper, challenges the PMM literature by defining the foundations of complexity in performance management, which also calls for a unique definition of complexity in PM. Future research should also seek to explore PMC in its two streams, i.e. social complexity and technical complexity. Second, this study investigated the mix between social and technical controls and how such a mix should be treated. As a contin- uation of this research, further studies may explore which specific factors and interactions between them induce complexity and to what extent. Additionally, more empirical research may unlock critical events from the external environment that are contingent on the practice of measurement and tend to induce complexity in the internal environment.

While interactions between the social and technical dimensions are difficult to manage, their divisions and interactions are quite crucial to facilitating responsiveness and dynamism in organizations. Having explored PMC, the study results suggest that complexity theory is an essential element for studying PMM complexity. In this paper, PMC was explored using the system perspective in vast complexity theory. For future studies, more perspectives could be explored: for example, using the hierarchical model by Simon (1996) that could break down PMM system into subsystems. It also suggests that, by understanding how complexity emerges, managers may rethink how they can better organize their use of controls to manage a PMS over its life cycle. Based on the SLR, the study has demonstrated how complexity emerges and is amplified in organizations, and it has attempted to identify ways of moderating complexity. Just like any research, SLR has its own limitations of which some papers will be missed out, despite selecting a comprehensive list of search strings. In order to mitigate this limitation, we followed citation tracking to ensure that important missed papers were recovered. The SLR in this study is completely reliant on previous published papers that may have different purpose. Therefore, we focused more on the objective of each paper to see its relevance to this study. Similarly, articles were filtered based on the appropriateness of the selection criteria. This study has attempted to mitigate this limitation by following thorough research protocols (Moustaghfir 2008; Tranfield et al. 2003). We urge more empirical studies to show how organizational controls and their interaction can actually moderate complexity over time. While many authors, such as Johnston (2005) and Bititci et al. (2012) acknowledge the need for social controls at each process stage, there is little consensus regarding how to strike the proper balance between the level of control and the level of freedom or autonomy given to individuals.

\section{References}

Adler, R.W. (2011). Performance management and organizational strategy: how to design systems that meet the 
needs of confrontation strategy firms. British Accounting Review, 43, pp. 251-263.

Aguinis, H., Joo, H. and Gottfredson, R.K. (2011). Why we hate performance management - and why we should love it. Business Horizons, 54, pp. 503-508.

Anderson, P.W. (1999). Complexity theory and organization science. Organization Science, 10, pp. 216-232.

Angelis, J. and Jordahl, H. (2015). Merciful yet effective elderly care performance management practices. Measuring Business Excellence, 19, pp. 61-69.

Ben Hadj Salem Mhamdia, A. (2013). Performance measurement practices in software ecosystem. International Journal of Productivity and Performance Management, 62, pp. 514-533.

Beer, H.A. and Micheli, P. (2017). How performance measurement influences stakeholders in not-for-profit organizations. International Journal of Operations \& Production Management, 37, pp. 1164-1184.

Bititci, U.S. (2015). Managing Business Performance. Hoboken, NJ: John Wiley.

Bititci, U.S., Garengo, P., Dörfler, V. and Nudurupati, S. (2012). Performance measurement: challenges for tomorrow. International Journal of Management Reviews, 14, pp. 305-327.

Bititci, U., Mendibil, K., Nudurupati, S.S. and Garengo, P. (2006). Dynamics of Performance Measurement and Organizational Culture. International Journal of Operations \& Production Management, 26. Available at: https://doi.org/10.1108/01443570610710579

Bititci, U.S., Mendibil, K., Martinez, V. and Albores, P. (2005). Measuring and managing performance in extended enterprises. International Journal of Operations \& Production Management, 25, pp. 333-353.

Bititci, U.S., Turner, Ut. and Begemann, C. (2000). Dynamics of performance measurement systems. International Journal of Operations \& Production Management, 20, pp. 692-704.

Bonatto, F., Resende, L.M.M. De, Betim, L.M., Pereira, R. Da S. and Agner, T. von (2015). Performance management in horizontal business networks: a systematic review. IFACPapersOnLine, 48, pp. 1827-1833.

Boulding, K.E. (1956). General systems theory-the skeleton of science. Management Science, 2, pp. 197-208.

Bourne, M., Mills, J., Wilcox, M., Neely, A. and Platts, K. (2000). Designing, implementing and updating performance measurement systems. International Journal of Operations \& Production Management, 20, pp. 754 771.

Bourne, M., Neely, A., Mills, J. and Platts, K. (2003). Implementing performance measurement systems: a literature review. International Journal Business Performance Management, 5, pp. 1-24.

Bourne, M., Neely, A., Platts, K. and Mills, J. (2002). The success and failure of performance measurement initiatives. International Journal of Operations \& Production Management, 22, pp. 1288-1310.
Braz, R.G.F., Scavarda, L.F. and Martins, R.A. (2011). Reviewing and improving performance measurement systems: an action research. International Journal of Production Economics, 133, pp. 751-760.

Briscoe, G., Keränen, K. and Parry, G. (2012). Understanding complex service systems through different lenses: an overview. European Management Journal, 30, pp. 418426.

Broadbent, J. and Laughlin, R. (2009). Performance management systems: a conceptual model. Management Accounting Research, 20, pp. 283-295.

Brown, S.L. and Eisenhardt, K.M. (1997). The art of continuous change: linking complexity theory and time-paced evolution in relentlessly shifting organizations. Administrative Science Quarterly, 42, pp. 1-34.

Buckingham, M. and Goodall, A. (2015). Reinventing performance management. Harvard Business Review, 93, pp. 40-50.

Burnes, B. (2005). Complexity theories and organizational change. International Journal of Management Reviews, 7(2), pp. 73-90.

Caniato, F., Luzzini, D. and Ronchi, S. (2014). Purchasing performance management systems: An empirical investigation. Production Planning and Control, 25, pp. 616-635.

Canonico, P., De Nito, E., Esposito, V., Martinez, M., Mercurio, L. and Pezzillo Iacono, M. (2015). The boundaries of a performance management system between learning and control. Measuring Business Excellence, 19, pp. 7-21.

Carlsson-Wall, M., Kraus, K. and Messner, M. (2016). Performance measurement systems and the enactment of different institutional logics: insights from a football organization. Management Accounting Research, 32, pp. 45-61.

Chalmeta, R., Palomero, S. and Matilla, M. (2012). Methodology to develop a performance measurement system in small and medium-sized enterprises, International Journal of Computer Integrated Manufacturing, 5, pp. 716740.

Choong, K.K. (2013). Understanding the features of performance measurement system: a literature review. Measuring Business Excellence, 17, pp. 102-121.

Choong, K.K. (2014). Has this large number of performance measurement publications contributed to its better understanding? A systematic review for research and applications. International Journal of Production Research, 52, pp. 4174-4197.

Cook, D.J., Mulrow, C. and Haynes, R. (1997). Systematic reviews: synthesis of best evidence for clinical decisions. Annals of Internal Medicine, 126, pp. 376-380.

Cook, D.J., Sackett, D.I. and Spitzer, W.O. (1995). Methodological guidelines for systematic reviews of randomized control trials in health care from the Potsdam Consultation on Meta-analysis. Journal of Clinical Epidemiology, 48, pp. $167-171$.

Courty, P. and Marschke, G. (2003). Dynamics of performance-measurement systems. Oxford Review of Economic Policy, 19, pp. 268-284. 
Davis, D.A., Thomson, M.A., Oxman, A.D. and Haynes, R.B. (1995). Changing physician performance: a systematic review of the effect of continuing medical education strategies. JAMA, 274, pp. 700-705.

de Waal, A. and Kourtit, K. (2013). Performance measurement and management in practice: advantages, disadvantages and reasons for use. International Journal of Productivity and Performance Management, 62, pp. 446-473.

Deng, F., Smyth, H. and Anvuur, A. (2012). A critical review of PMS in construction: towards a research agenda. In Smith, S.D. (ed.), Proceedings of the 28th ARCOM Conference, Edinburgh, September 2012. Reading: Association of Researchers in Construction Management, pp. 807-816. Available at: http://discovery.ucl.ac.uk/1358228/.

Dewettinck, K. and Vroonen, W. (2017). Antecedents and consequences of performance management enactment by front-line managers. Evidence from Belgium. International Journal of Human Resource Management, 28, pp. 2473-2502.

Edmonds, B. (1999). Syntactic measures of complexity. Doctoral thesis, University of Manchester, Manchester, UK.

Elg, M., Palmberg Broryd, K. and Kollberg, B. (2013). Performance measurement to drive improvements in healthcare practice. International Journal of Operations \& Production Management, 33, pp. 1623-1651.

Elzinga, T., Albronda, B. and Kluijtmans, F. (2009). Behavioral factors influencing performance management systems' use. International Journal of Productivity and Performance Management, 58, pp. 508-522.

Ferreira, A. and Otley, D. (2009). The design and use of performance management systems: an extended framework for analysis. Management Accounting Research, 20, pp. 263-282.

Folan, P. and Browne, J. (2005). A review of performance measurement: towards performance management. Computers in Industry, 56, pp. 663-680.

Forcada, N., Serrat, C., Rodríguez, S. and Bortolini, R. (2017). Communication key performance indicators for selecting construction project bidders. Journal of Management in Engineering, 33, pp. 4017033.

Franco-Santos, M., Kennerley, M., Micheli, P., Martinez, V., Mason, S., Marr, B., Gray, D. and Neely, A. (2007). Towards a definition of a business performance measurement system. International Journal of Operations \& Production Management, 27, pp. 784-801.

Franco-Santos, M., Lucianetti, L. and Bourne, M. (2012). Contemporary performance measurement systems: a review of their consequences and a framework for research. Management Accounting Research, 23, pp. 79-119.

Garengo P. and Sharma M.K. (2014). Performance measurement system contingency factors: a cross analysis of Italian and Indian SMEs, Production Planning and Control, 25, pp. 220-240.

Garengo, P., Biazzo, S. and Bititci, U.S. (2005). Performance measurement systems in SMEs: a review for a research agenda. International Journal of Management Reviews, 7, pp. $25-47$.

Galbraith, J.R. (1982). Designing the innovating organization. Organizational Dynamics, 10, pp. 5-25.

Geraldi, J., Maylor, H. and Williams, T. (2011). Now, let's make it really complex (complicated). International Journal of Operations \& Production Management, 31, pp. 966990.

Ginieis, M., Sánchez-Rebull, M.V. and Campa-Planas, F. (2012). The academic journal literature on air transport: analysis using systematic literature review methodology. Journal of Air Transport Management, 19, pp. 3135.

Greiling, D. (2005). Performance measurement in the public sector: the German experience. International Journal of Productivity and Performance Management, 54, pp. 551567.

Grobman, G.M. (2005). Complexity theory: a new way to look at organizational change. Public Administration Quarterly, 29, pp. 351-384.

Govindan, K., Mangla, S.K. and Luthra, S. (2017). Prioritising indicators in improving supply chain performance using fuzzy AHP: insights from the case example of four Indian manufacturing companies. Production Planning \& Control, 28, pp. 552-573.

Hansen, A. (2010). Nonfinancial performance measures, externalities and target setting: a comparative case study of resolutions through planning, Management Accounting Research, 21, pp. 17-39.

Haponava, T. and Al Jibouri, S. (2009). Identifying key performance indicators for use in control of pre project stage process in construction. International Journal of Productivity and Performance Management, 58, pp. 160173.

Harkness, M. and Bourne, M. (2015). Is complexity a barrier to the practice of performance measurement? In Proceedings of the Performance Management Association Conference, Auckland.

Holland, J.H. (1975). Adaptation in Natural and Artificial Systems. Cambridge, MA: MIT Press.

Hudson, M., Lean, J. and Smart, P. (2001). Improving control through effective performance measurement in SMEs. Production, 12, pp. 804-813.

Hwang, G., Lee, J., Park, J. and Chang, T-.W. (2017). Developing performance measurement system for Internet of Things and smart factory environment. International Journal of Production Research, 55, pp. 2590-2602.

Jääskeläinen, A. and Laihonen, H. (2013). Overcoming the specific performance measurement challenges of knowledge-intensive organizations. International Journal of Productivity and Performance Management, 62, pp. 350-363.

Jääskeläinen, A. and Sillanpää, V. (2013). Overcoming challenges in the implementation of performance measurement. International Journal of Public Sector Management, 26, pp. 440-454. 
Jain, S., Triantis, K.P. and Liu, S. (2011). Manufacturing performance measurement and target setting: a data envelopment analysis approach. European Journal of Operational Research, 214, pp. 616-626.

Johnston, J. (2005). Performance measurement uncertainty on the Grand Canal: ethical and productivity conflicts between social and economic agency? International Journal of Productivity and Performance Management, 54, pp. 595-612.

Jones, O. and Gatrell, C. (2014). Editorial: the future of writing and reviewing for IJMR. International Journal of Management Reviews, 16, pp. 249-264.

Kandjani, H. and Bernus, P. (2012). Towards a cybernetic theory and reference model of self-designing complex collaborative networks. Collaborative Networks in the Internet of Services, 380, pp. 485-493.

Kang, N., Zhao, C., Li, J. and Horst, J.A. (2016). A hierarchical structure of key performance indicators for operation management and continuous improvement in production systems. International Journal of Production Research, 54, pp. 6333-6350.

Kauppi, K. (2013). Extending the use of institutional theory in operations and supply chain management research: review and research suggestions. International Journal of Operations \& Production Management, 33, pp. 13181345.

Kelman, S. and Friedman, J.N. (2009). Performance improvement and performance dysfunction: an empirical examination of distortionary impacts of the emergency room wait-time target in the English National Health Service. Journal of Public Administration Research and Theory, 19, pp. 917-946.

Kennerley, M. and Neely, A. (2002). A framework of the factors affecting the evolution of performance measurement systems. International Journal of Operations \& Production Management, 22, pp. 1222-1245.

Ladyman, J., Lambert, J. and Wiesner, K. (2013). What is a complex system? European Journal for Philosophy of Science, 3, pp. 33-67.

Laihonen, H., Jääskeläinen, H. and Pekkola, S. (2014). Measuring performance of a service system from organizations to customer-perceived performance. Measuring Business Excellence, 18, pp. 73-86.

Laihonen, H. and Pekkola, S. (2016). Impacts of using a performance measurement system in supply chain management: a case study. International Journal of Production Research, 54, pp. 5607-5617.

Lewis, M.A. (2003). Analysing organisational competence: implications for the management of operations. International Journal of Operations \& Production Management, 23, pp. 731-756.

Lin, Y.H., Chen, C-.C., Tsai, C.F.M. and Tseng, M-.L. (2014). Balanced scorecard performance evaluation in a closed-loop hierarchical model under uncertainty. Applied Soft Computing Journal, 24, pp. 10221032.
Lohman, C., Fortuin, L. and Wouters, M. (2004). Designing a performance measurement system: a case study. European Journal of Operational Research, 156, pp. 267-286.

López-Illescas, C., Moya-Anegón, F. and Moed, H.F. (2008). Coverage and citation impact of oncological journals in the Web of Science and Scopus. Journal of Informetrics, 2, pp. 304-316.

Mason-Jones, R. and Towill, D.R. (2000). Designing, implementing and updating performance measurement system. International Journal of Operations and Production Management, 20, pp. 754-771.

McAdam, R. and Bailie, B. (2002). Business performance measures and alignment impact on strategy. International Journal of Operations \& Production Management, 22, pp. 972-996.

McGovern, P. (2014). Contradictions at work: a critical review. Sociology, 48, pp. 20-37.

Melnyk, S.A., Bititci, U.S., Platts, K., Tobias, J. and Andersen, B. (2014). Is performance measurement and management fit for the future? Management Accounting Research, 25, pp. 173-186.

Micheli, P. and Kennerley, M. (2005). Performance measurement frameworks in public and non-profit sectors. Production Planning \& Control, 16, pp. 125-134.

Micheli, P. and Mari, L. (2014). The theory and practice of performance measurement. Management Accounting Research, 25, pp. 147-156.

Miller, D. and Friesen, P.H. (1984). A longitudinal study of the corporate life cycle. Management Science, 30, pp. 1161-1183.

Mol, N.P. and Beeres, R.J.M. (2005). Performance management in a setting of deficient output controls. International Journal of Productivity and Performance Management, 54, pp. 533-550.

Morel, B. and Ramanujam, R. (1999). Through the looking glass of complexity: the dynamics of organizations as adaptive and evolving systems. Organization Science, 10, pp. 278-293.

Moustaghfir, K. (2008), The dynamics of knowledge assets and their link with firm performance. Measuring Business Excellence, 12, pp. 10-24.

Neely, A. (2005). The evolution of performance measurement research. International Journal of Operations \& Production Management, 25, pp. 1264-1277.

Neely, A. (1999). The performance measurement revolution: why now and what next? International Journal of Operations \& Production Management, 19, pp. 205-228.

Neely, A., Mills, J., Platts, K., Richards, H., Gregory, M., Bourne, M. and Kennerley, M. (2000). Performance measurement system design: developing and testing a processbased approach. International Journal of Operations \& Production Management, 20, pp. 1119-1145.

Ngai, E.W.T. and Cheng, T.C.E. (2001). A knowledge-based system for supporting performance measurement of AMT projects: a research agenda. International Journal of $\mathrm{Op}$ erations \& Production Management, 21, pp. 223-233. 
Nudurupati, S.S. and Bititci, U.S. (2005). Implementation and impact of IT-supported performance measurement systems. Production Planning \& Control, 16, pp. 152162.

Nudurupati, S.S., Bititci, U.S., Kumar, V. and Chan, F-T.S. (2011). State of the art literature review on performance measurement. Computers and Industrial Engineering, 60, pp. 279-290.

Nudurupati, S.S., Tebboune, S. and Hardman, J. (2016). Contemporary performance measurement and management (PMM) in digital economies. Production Planning and Control, 27, pp. 226-235.

Paranjape, B., Rossiter, M. and Pantano, V. (2006). Performance measurement systems: successes, failures and future - a review. Measuring Business Excellence, 10, pp. 4-14.

Pavlov, A. and Bourne, M. (2011). Explaining the Effects of Performance Measurement on Performance: An Organizational Routines Perspective. International Journal of Operations \& Production Management, 31, pp. 101122.

Pavlov, A., Mura, M., Franco-Santos, M. and Bourne, M. (2017). Modelling the impact of performance management practices on firm performance: interaction with human resource management practices. Production Planning \& Control, 28, pp. 431-443.

Pekkola, S. and Ukko, J. (2016). Designing a performance measurement system for collaborative network. International Journal of Operations \& Production Management, 36, pp. 1410-1434

Pellinen, J., Teittinen, H. and Järvenpää, M. (2016). Performance measurement system in the situation of simultaneous vertical and horizontal integration. International Journal of Operations \& Production Management, 36, pp. $1182-1200$.

Petticrew, M. and Robert, H. (2006). Why do we need systematic reviews? Systematic Reviews in the Social Sciences: A Practical Guide, Chapter 1. Oxford: Blackwell, pp. 1-27.

Pettigrew, A.M. (1977). Strategy formulation as a political process. International Studies of Management \& Organization, 7, pp. 78-87.

Pettigrew, A.M. (2014). The Politics of Organizational Decision-Making. Abingdon: Routledge.

Pongatichat, P. and Johnston, R. (2008). Exploring strategy-misaligned performance measurement, International Journal of Productivity and Performance Management, 57, pp. 207-222.

Rahbek, Gjerdrum, Pedersen, E. and Sudzina, F. (2012). Which firms use measures? International Journal of Operations \& Production Management, 32, pp. 4-27.

Ribeiro-Carpinetti, L.C., Cardoza Galdámez, E. and Cecilio Gerolamo, M. (2008). A measurement system for managing performance of industrial clusters. International Journal of Productivity and Performance Management, 57, pp. 405-419.
Rizzo, J.R., House, R.J. and Lirtzman, S.I. (1970). Role conflict and ambiguity in complex organizations. Administrative Science Quarterly, 15, pp. 150-163.

Roehrich, J. and Lewis, M. (2014). Procuring complex performance: implications for exchange governance complexity. International Journal of Operations \& Production Management, 34, pp. 221-241.

Sacristán-Díaz, M., Álvarez-Gil, M.J. and DominguezMachuca, J.A. (2005). Performance measurement systems, competitive priorities, and advanced manufacturing technology: some evidence from the aeronautical sector. International Journal of Operations \& Production Management, 25, pp. 781-799

Sahin, E., Vidal, L.-A. and Benzarti, E. (2013). A framework to evaluate the complexity of home care services. Kybernetes, 42, pp. 569-592.

Santos, S.P., Belton, V. and Howick, S. (2002). Adding value to performance measurement by using system dynamics and multicriteria analysis. International Journal of Operations \& Production Management, 22, pp. 1246-1272.

Sharma, M.K. and Bhagwat, R. (2006). Performance measurements in the implementation of information systems in small and medium-sized enterprises: a framework and empirical analysis. Measuring Business Excellence, 10, pp. 8-21.

Shin, D. and Konrad, A.M. (2017). Causality between highperformance work systems and organizational performance. Journal of Management, 43, pp. 973-997.

Sillanpää, V. (2011). Performance measurement in welfare services: a survey of Finnish organisations. Measuring Business Excellence, 15, pp. 62-70.

Simon, H.A. (1996). The architecture of complexity: hierarchic systems. Sciences of the Artificial, 106, pp. 467482.

Smith, M. and Bititci, U.S. (2017). Interplay between performance measurement and management, employee engagement and performance. International Journal of Operations \& Production Management, 37, pp. 1207-1228.

Spekle, R.F. and Verbeeten, F. (2014). The use of performance measurement systems in the public sector: effects on performance. Management Accounting Research, 25, pp. 131-146.

Stacey, R.D. (1995). The science of complexity: an alternative perspective for strategic change processes. Strategic Management Journal, 16, pp. 477-495.

Sullivan, T. (2011). Embracing complexity. Harvard Business Review, (14 sept 2017), pp. 89-93. Available at: http://opus.bath.ac.uk/26603/.

Suprapto, B., Wahab, H.A. and Wibowo, A.J. (2009). The Implementation of balance score card for performance measurement in small and medium enterprises: evidence from Malaysian health care services. Asian Journal of Technology Management, 2(2), pp. 76-87.

Suwingnjo, P., Bitici, U. and Carrie, A.P. (2000). Quantitative Models for Performance Measurement System. International Journal of Production Economics, 64, pp. 231-241. 
Tasca, J.E., Ensslin, L., Ensslin, S.R. and Martins Alves, M.B. (2010). An approach for selecting a theoretical framework for the evaluation of training programs. Journal of European Industrial Training, 34, pp. 631-655.

Taticchi P., Balachandran K. and Tonelli F. (2012). Performance measurement and management systems: state of the art, guidelines for design and challenges. Measuring Business Excellence, 16, pp. 41-54.

Taylor, A. and Taylor, M. (2014). Factors influencing effective implementation of performance measurement systems in small and medium-sized enterprises and large firms: a perspective from Contingency Theory. International Journal of Production Research, 52, pp. 847866.

Toor, S.-R. and Ogunlana, S.O. (2010). Beyond the 'iron triangle': stakeholder perception of key performance indicators (KPIs) for large-scale public sector development projects. International Journal of Project Management, 28, pp. 228-236.

Tranfield, D., Denyer, D. and Smart, P. (2003). Towards a methodology for developing evidence-informed management knowledge by means of systematic review. British Journal of Management, 14, pp. 207-222.

Tung, A., Baird, K. and Schoch, H.P. (2011). Factors influencing the effectiveness of performance measurement systems. International Journal of Operations \& Production Management, 31, pp. 1287-1310.

Turner, T.J., Bititci, U.S. and Nudurupati, S.S. (2005), Implementation and impact of performance measures in two SMEs in Central Scotland. Production Planning \& Control, 16, pp. 135-151.

Turner, N., Swart, J. and Maylor, H. (2013). Mechanisms for managing ambidexterity: a review and research agenda. International Journal of Management Reviews, 15, pp. 317-332.

Upadhaya, B., Munir, R. and Blount, Y. (2014). Association between performance measurement systems and organisational effectiveness. International Journal of Operations and Production Management, 34, pp. 853-875.

Ukko, J., Tenhunen, J. and Rantanen, H. (2007). Performance measurement impacts on management and leadership: Perspectives of management and employees. International Journal of Production Economics, 110, pp. 3951.

Valmohammadi, C. and Servati, A. (2011). Performance measurement system implementation using Balanced Scorecard and statistical methods. International Journal of Productivity and Performance Management, 60, pp. 493511. van Veen-Dirks, P. (2010). Different uses of performance measures: the evaluation versus reward of production managers. Accounting, Organizations and Society, 35, pp. 141-164.

Vernadat F., Shah L., Etienne A. and Siadat A. (2013). VR-PMS: a new approach for performance measurement and management of industrial systems, International Journal of Production Research, 51, pp. 7420-7438.

Vidal, L.-A. and Marle, F. (2008). Understanding project complexity: implications on project management. Kybernetes, 37, pp. 1094-1110.

von Bertalanffy, L. (1969). General System Theory: Foundations, Development, Applications. New York, NY: Braziller.

Wilkinson, I.F. (2006). The evolution of an evolutionary perspective on B2B business. Journal of Business \& Industrial Marketing, 21, pp. 458-465.

Wood, R.E. (1986). Task complexity: definition of the construct. Organizational Behavior and Human Decision Processes, 37, pp. 60-82.

Wijngaard, J., de Vries, J. and Nauta, A. (2006). Performers and performance: how to investigate the contribution of the operational network to operational performance. International Journal of Operations \& Production Management, 26, pp. 394-411.

Wolf, F.M., Shea, J.A. and Albanese, M.A. (2001). Toward setting a research agenda for systematic reviews of evidence of the effects of medical education. Teaching and Learning in Medicine, 13, pp. 54-60.

Wouters, M. and Sportel, M. (2005). The role of existing measures in developing and implementing performance measurement systems. International Journal of Operations \& Production Management, 251, pp. 1062-1082.

Yilmaz, Y. and Bititci, U.S. (2006). Performance measurement in the value chain: manufacturing v. tourism. International Journal of Productivity and Performance Management, 55, pp. 371-389.

Zellner, M.L. (2008). Embracing complexity and uncertainty: the potential of agent-based modeling for environmental planning and policy. Planning Theory \& Practice, 9, pp. 437-457.

Zhang, H., Van de Walle, S. and Zhuo, Y. (2016a). Does trust in the performance measurement organization influence how public managers use performance information? Public Performance \& Management Review, 40, pp. 409-430.

Zhang, X., Van Donk, D.P. and van der Vaart, T. (2016b). The different impact of inter-organizational and intraorganizational ICT on supply chain performance. International Journal of Operations \& Production Management, 36, pp. 803-824. 